NASA Technical Memorandum 105557

\title{
Detecting Lamb Waves With Broad-Band Acousto-Ultrasonic Signals in Composite Structures
}

Harold E. Kautz

Lewis Research Center

Cleveland, Ohio

March 1992

\section{N/SN}


$m=\cdots$

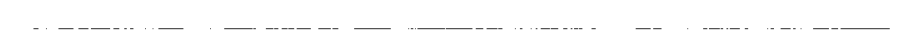




\title{
DETECTING LAMB WAVES WITH BROADBAND ACOUSTO-ULTRASONIC SIGNALS IN COMPOSITE STRUCTURES
}

\author{
Harold E. Kautz \\ National Aeronautics and Space Administration \\ Lewis Research Center \\ Cleveland, Ohio 44135
}

\section{INTRODUCTION}

The present investigation is concerned with developing methods to monitor mechanical properties of various types of composites for aerospace applications. These include high temperature fiber reinforced polymers as well as ceramic matrix composites (CMC) and metal matrix composites (MMC). The investigation employs the acousto-ultrasonic (AU) configuration of Ref. [1] with broadband sending and receiving transducers for producing and detecting ultrasonic waves. With the AU approach, it is possible to observe discrete pulses in the signal. The ultrasonic velocities of these pulses proved sensitive to variations in stiffness modulus and fiber/matrix interfacial shear strength in CMC's [2]. It was theorized that Lamb waves are produced with the AU configuration in MMC structures [3] and CMC structures [2]. There is a need to clarify the nature of the Lamb wave modes and to show how they can be used to assess material properties and boundary conditions. It is hoped to thereby demonstrate a method for monitoring mechanical properties of composites of aerospace interest.

In our present work we identify the above-mentioned discrete pulses as Lamb waves by constructing dispersion curves for CMC and MMC specimens. These dispersion curves are compared to the theory developed in Ref. [4] for polymer composites.

\section{THEORETICAL}

\section{Application of Approximate Theory for Lamb Waves in Composites}

Among the earliest studies of plate waves in structures were those of H. Lamb in 1917 [5]. Recently, Tang and Henneke [4] studied the behavior of these waves in orthotropic fiber 
reinforced polymer structures. Tang and Henneke [6] successfully detected changes in Lamb wave geometrical dispersion curves due to axial stiffness loss produced by transply cracking.

Lamb [5] presented the solutions for ultrasonic wave propagation in an isotropic thin plate. This type of wave propagation is now referred to as the Lamb wave mode. A thin plate is defined as having a thickness, $h$, on the order of the wave length of a bulk wave in the medium. Under this condition the ultrasonic energy propagates as waves undergoing multiple reflections from the opposite surfaces. Individual propagation paths loose their identity due to superposition, and geometrical dispersion occurs. The situation is similar to electromagnetic waves in a wave guide. For Lamb waves in a plate, however, the propagation radiates out in a plane rather than a single direction.

It was recognized for some time [7-12] that Lamb wave analysis is of value with $\mathrm{AU}$ in some composite structures. However the Lamb solutions take advantage of symmetries associated with an isotropic plate. These symmetries are generally not found in composites. Tang, Henneke, and Stiffler [13] developed an approximate theory for Lamb wave solutions in laminated composites. Figure 1 is taken from Ref. [4]. Figure 1 shows computed Lamb wave geometrical dispersion curves for propagation parallel to the fibers in a unidirectional plate of the graphite/epoxy system: AS-4(GR)/Pr 288. In Fig. 1, frequency multiplied by specimen thickness, fh, is plotted against wave number multiplied by thickness, kh. The abscissa, $\mathrm{kh}=2 \pi(\mathrm{h} / \lambda)$. The ordinate, fh, is a velocity. It has been pointed out $[14]$ that where the curves for the various Lamb modes intersect the ordinate the product fh is the velocity of through-thickness resonance waves. The inclusion of $h$ in the variables of Fig. 1 has the merit of normalizing the results for use with plates of any thickness.

The symmetric modes are dilatation waves. This means that their passage causes cycles of simultaneous outward and then inward surface displacement on the opposite sides of the plate. 
In contrast, the antisymmetric modes are flexure waves. Outward surface displacement on one side of the plate is opposed by inward displacement on the other.

By definition [15]:

$$
\begin{gathered}
\text { Group velocity } V_{g}=d \omega / d k \\
\text { Phase velocity } V_{p}=\omega / k
\end{gathered}
$$

$\mathrm{k}$ is the wave number which is $2 \pi / \lambda, \omega$ is radial frequency. As with Ref. [4], we construct dispersion curves using cycle frequency $f=\omega / 2 \pi$.

$$
\text { Dispersion occurs when } V_{g} \neq V_{p}
$$

It is evident in Fig. 1 that most Lamb modes, (e.g., the ones that do not pass through the origin), are highly dispersive. This can be seen by considering the phase and group velocity at some point on one of these curves. The phase velocity is $2 \pi$ times the slope of a line connecting the chosen point to the origin. The group velocity is $2 \pi$ times the slope of a line tangent to the curve at the point. For the very dispersive modes shown, phase velocity is always greater than group velocity.

Nondispersive modes, or nearly nondispersive, shown in Fig. 1 are linear segments with intercepts near the origin. The lowest two curves and various curve segments fit into this category. For these, $\mathrm{V}_{\mathrm{g}} \approx \mathrm{V}_{\mathrm{p}}$. In the $\mathrm{AU}$ configuration one expects that pulses leaving the sending transducers in the $f$ and $k$ regimes of these modes will retain their discrete nature in transit from sender to receiver whereas the other modes will tend to disperse the pulses into a much broader time domain signal. This being so, the nondispersive modes ought to be distinguishable from the rest of the signal. The lowest antisymmetric mode, which is nearly nondispersive, is unique with respect to the rest of the modes in that it has phase velocity less than group velocity over the entire range shown. No other mode has phase velocity less than group velocity. This characteristic could be used to identify the lowest antisymmetric mode. 
As kh increase, the above becomes less applicable because in the limit frequency increases and wave length decreases. Higher frequency leads to greater attenuation and greater difficulty in collecting a usable signal. Shorter wave lengths lead to interactions with material point features for wavelengths much less than $h$. As a result Lamb waves will tend not to propagate. What is left of the signal becomes stochastic and Lamb wave analysis does not apply.

\section{Sensitivity of Lamb Waves to Mechanical Properties in Composites}

The wave equation for the lowest symmetric mode for "symmetric cross-ply and quasiisotropic" laminates is [4]:

$$
\mathrm{A}_{11} \mathrm{k}^{2}-\rho \omega^{2}=0
$$

$A_{11}$ is an extension stiffness in the propagation direction. $\rho$ is the mass density integrated through the thickness of the plate. Equation (4) shows that the phase velocity, $V_{p}=\omega / k$, of the first symmmetric mode pulse is sensitive to the stiffness modulus in the propagation direction.

The solution for the lowest antisymmetric mode for the symmetric cross-ply layup is:

$$
\left(D_{11} k^{2}+A_{55}-I \omega^{2}\right)\left(A_{55} k^{2}-\rho \omega^{2}\right)-A_{55}{ }^{2} k^{2}=0
$$

$D_{11}$ is a bending stiffness, $A_{55}$ is a shear stiffness, and $I$ is a density integral. Solutions for the lowest antisymmetric mode in other layups are more complex than Eq. (5). However, in each antisymmetric case the Lamb mode is dependent on shear and flexure properties of the composite [4].

\section{EXPERIMENTAL}

\section{Specimens Used in the Study}

Tensile specimens were [0] unidirectional SiC/RBSN CMC (SiC fiber reinforced reaction bonded silicon nitride ceramic matrix composite). Details on the fabrication and properties of this material are in Ref. [2]. Unidirectional SiC-6/Ti 15-3 MMC panels were also tested. Details on fabrication and properties of this material are in Ref. [3]. The specimens are summarized in Table II. 


\section{Collection of Acousto-Ultrasonic Data}

Figure 2 shows the AU experimental configuration that was employed. Several combinations of broadband transducers were tried. Best results for MMC's and CMC's were obtained with pairs of $1.0 \mathrm{MHz}$ center frequency and with pairs of $0.5 \mathrm{MHz}$ center frequency transducers. Elastomer dry couplant pads, 0.32 by $1.27 \mathrm{~cm}$, were bonded to the transducer wear plates and were oriented with long direction perpendicular to the propagation path. The path length, $s$, is the distance from sender to receiver.

Waveforms were collected from the receiving transducer response, digitized and stored on disk. Details of the procedure are described in Ref. [1].

\section{Determination of Group Velocity of Ultrasonic Pulses}

Figures 3 to 5 are a sequence of waveforms collected in the AU configuration on the same [0] unidirectional SiC fiber/RBSN matrix CMC tensile specimen. They show typical data collected with, respectively, pairs of $2.25,1.0$, and $0.5 \mathrm{MHz}$ broadband transducers. Table I has been constructed in order to estimate what modes these waveforms appear to correspond to relative to the Fig. 1 dispersion curves. The comparison is done for the vertical axis, fh, in two steps: First the product $\mathrm{f}$ (center frequency) $\mathrm{X} \mathrm{h}(0.22 \mathrm{~cm})$ in meters/second is calculated. Second, the fh values are scaled from CMC to graphite/polymer (GP) values by the transformation:

$$
\mathrm{fh}_{\mathrm{GP}} \rightarrow \mathrm{fh}_{\mathrm{CMC}}\left(\mathrm{V}_{\mathrm{GP}} / \mathrm{V}_{\mathrm{CMC}}\right)
$$

This is done because the dispersion curves intersect the fh axis at through-thickness resonance values [14]. Resonance frequency is proportional to velocity in the thickness direction [3]. $V_{G P}$ is through thickness velocity in the graphite/polymer and is taken as $0.27 \mathrm{~cm} / \mu \mathrm{sec}$ [3]. $\mathrm{V}_{\mathrm{CMC}}$ is through thickness velocity in the 30 percent porous $\mathrm{CMC}$ and is taken as $0.8 \mathrm{~cm} / \mu \sec [16]$. Note that the Eq. (6) scaling has greatest validity at the fh axis of the dispersion curve. 
Figure 3 shows a typical AU signal collected with a pair of $2.25 \mathrm{MHz}$ transducers. The total coupling force on the transducers was $12 \mathrm{~N}$, or an average pressure of $15 \mathrm{~N} / \mathrm{cm}^{2}$. The transducer frequency and the coupling pressure are typical of earlier AU work [1]. This coupling pressure to the specimen has been found to be optimum to assure reproducible signals and relatively low attenuation. Table I indicates that the transducer center frequency times thickness (after scaling) is equivalent to $1688 \mathrm{~m} / \mathrm{sec},(0.1688 \mathrm{~cm} / \mu \mathrm{sec}$.), on the $\mathrm{fh}$ axis of Fig. 1. This is a region where very dispersive Lamb modes arise.

Decreasing the coupling pressure to about $3.5 \mathrm{~N} / \mathrm{cm}^{2}$ decreases the high frequency signal components and reveals the presence of the lowest Lamb modes. Employing two $1.0 \mathrm{MHz}$ transducers under these conditions yields waveforms such as the example in Fig. 4. Three pulses are evident. The earliest arriving pulse is labeled pulse 1 and the next is labeled pulse 2. By investigating the relation between the positions of the transducers on the specimen and the pulse arrivals it can be determined that pulses 1 and 2 travel exactly the path length $s$ between the sender and the receiver. At the same time, it becomes evident that the last arriving pulse is the echo of pulse 2 after reflecting from the end of the specimen. If two $0.5 \mathrm{MHz}$ transducers are employed under these conditions waveforms are collected such as the example in Fig. 5. With two $0.5 \mathrm{MHz}$ transducers pulse 1 is often unresolvable. However, pulse 2 and its echo are more distinct. Table I shows that the transducer center frequencies for the specimen thickness employed in these two cases are equivalent to Fig. 1 fh values $372 \mathrm{~m} / \mathrm{sec}(0.0372 \mathrm{~cm} / \mu \mathrm{sec}$.), and $743 \mathrm{~m} / \mathrm{sec}(0.0743 \mathrm{~cm} / \mu \mathrm{sec})$. This is where the lowest symmetric and antisymmetric modes are found.

Figure 1 shows that the antisymmetric mode has the lower slope and, from Eq. (1), the lower group velocity. Lower velocity means later arrival as the case of pulse 2 relative to pulse 1. Hence, we identify pulse 2 as the lowest antisymmetric Lamb mode. We identify 
pulse 1 as the lowest symmetric Lamb mode up to the break in that curve. Beyond that it is likely to represent higher symmetric mode segments.

We will consider arrival times for pulses 1 and 2 that have traveled exactly the distance $s$ from sending transducer to receiving transducer. This introduces the need for windowing out unwanted pulses in the signal.

In order to determine the velocities associated with these pulses data was collected over a range of seven transducer separations, $s$, ranging from 3.81 to $7.0 \mathrm{~cm}$. The pulse arrival times, $t$, were linearly regressed against the $\mathrm{s}$ values and the slope was taken as the pulse velocity [2]. This is shown in Fig. 6.

\section{Determination of Phase Velocities}

Phase velocities are calculated at frequencies suggested by the pulse data. For example, pulse 2 (antisymmetric mode) in a CMC tensile specimen with $\mathrm{h}=0.216 \mathrm{~cm}$ has a center frequency of about $0.5 \mathrm{MHz}$. Phase velocity is calculated at values from 0.3 to $0.7 \mathrm{MHz}$ for the pulse. Similarly, the symmetric pulse 1 was centered at $0.9 \mathrm{MHz}$. Phase velocities were determined for 0.5 to $1.3 \mathrm{MHz}$ at the arrival of this pulse.

Phase arrival time is determined as follows:

1. The signal is square wave windowed around the already determined pulse arrival time, $t_{1}$. For determining phase velocity for frequency $f$, the window used was $t_{1} \pm 1 / f$. In most applications, one avoids a square window to avoid unwanted high frequency components. However, in this case a square wave is desirable because it does not change the shape, and thus the phases of the frequencies of interest.

2. The windowed signal is Fourier transformed.

3. A sine wave is constructed using the phase associated with the frequency component interest, $\mathrm{f}$, in the Fourier transform. 
4. The sine wave is windowed in the interval $t_{1} \pm 1 / 2 \mathrm{f}$. This interval will contain exactly one cycle of frequency $f$, and therefore one peak, (at sine $(\pi / 2)$ ). The sine wave will have the same phase as the frequency component $f$ in the original pulse.

5. The peak of the windowed sine wave is taken as reference time, $t_{2}$, for progress of the phase of frequency $f$ as the transducer separation, $s$, is changed.

See Appendix I for more detail on determining group arrival times, $t_{1}$ and phase reference times, $\mathbf{t}_{\mathbf{2}}$.

As with the pulse calculations, transducer separations, $s$, and arrivals, $t_{2}$, are regressed. The change in arrival time of a reference peak in the sine wave is recorded as separation $s$ is increased. For the first $s$ value used in a set of data the pulse arrival, $t_{1}$, and phase reference peak, $t_{2}$, will be separated by a time interval of no more than $1 / f$. However, when group and phase velocity differ (as we expect with the antisymmetric mode), $t_{1}$ and $t_{2}$ can move apart. Eventually we may have to deal with situations depicted in the sequence of Figs. 7 and 8 . In Fig. 7 the transducer separation, $s$, is plotted against arrival time of a peak of the $\mathrm{f}=0.4 \mathrm{MHz}$ sine wave. After the fifth point, the peak being followed has moved out of the window and the peak of the next cycle has replaced it. In Fig. 8 the arrival times after the fifth are adjusted to the original peak by the transformation:

$$
t_{2} \rightarrow t_{2}+1 / f
$$

In this example the arrivals are increased by $2.5 \mu \mathrm{sec}$.

Once the phase velocity is determined, wave number, $k$, can be calculated from Eq. (2).

\section{$\underline{\text { Precision in Velocity Determination }}$}

Separation, s, ranged from 3.81 to $7.0 \mathrm{~cm}$ in $0.5 \mathrm{~cm}$ steps. As shown in Fig. 4, both pulse 1 (lowest symmmetric mode) and pulse 2 (lowest antisymmetric mode) data were available with 1.0 $\mathrm{MHz}$ transducer waveforms. In addition, sometimes both kinds of data were available with 
$0.5 \mathrm{MHz}$ transducers. In every experiment the most precise velocities were obtained when 1.0 $\mathrm{MHz}$ was used with pulse 1 and $0.5 \mathrm{MHz}$ was used with pulse 2.

For the work in Ref. [2] four group velocity determinations were made on each specimen for each of the two Lamb modes. From this it was determined that the antisymmetric mode average $V_{g}$ generally had a standard deviation below 2.5 percent. The standard deviation for symmetric mode $V_{g}$ were as high as 10 percent.

Phase velocities standard deviation was about the same as that of group velocities although sometimes a much smaller transducer separation range was employed. The symmetric mode pulses were sufficiently nondispersive so that the pulses did not change shape significantly over the same $s$ range as used for group velocity. In the case of the antisymmetric mode there was enough dispersion so that a shorter interval between $s$ values was required so as not to lose track of the reference peak. In this case, phase velocity $s$ ranged from 4.1 to $4.9 \mathrm{~cm}$ in $0.1 \mathrm{~cm}$ steps. Antisymmetric pulses were always so pronounced that the change did not effect precision. Therefore, the same standard deviation for the average of a set of four determinations of $V_{p}$ held as quoted above for $\mathrm{V}_{\mathrm{g}}$.

\section{RESULTS AND DISCUSSION}

\section{Group Velocities and Mechanical Properties}

Figure 9 shows plots of the lowest symmetric mode (pulse 1) and the lowest antisymmetric mode (pulse 2) group velocities versus angle between propagation path and fiber orientation for a unidirectional SiC/Ti 15-3 MMC panel. This is specimen 5 in Table II. Note that the pulse 1 velocity is strongly dependent on direction. It is maximum when parallel to the fibers. The greater the angle between fiber direction and wave path, the lower the velocity.

Figure 10 shows axial modulus of $\mathrm{SiC} / \mathrm{Ti}$ 15-3 specimens from tensile tests reported in Ref. [3]. The greater the angle between fibers and axial direction in the tensile specimens, the lower the modulus. This parallel behavior between group velocity and axial modulus is 
predicted for the lowest symmetric Lamb mode in Eq. (4). The antisymmetric mode (pulse 2) group velocity also shows a slight indication of the same behavior. These plots are taken as indication of the mechanical property sensitivity discussed in conjunction with Eqs. (4) and (5).

In Ref. [2] it was shown that the group velocity of the pulses is sensitive to mechanical properties in $\mathrm{SiC} / \mathrm{RBSN}$ composite tensile specimens. In that investigation, specimens with the standard "double carbon coated" SCS-6 SiC fibers were compared to specimens with nondouble coated SCS-0. The SCS-0 always exhibited higher fiber/matrix interfacial shear strength than SCS-6. This is reflected in the difference in pulse 2 velocity for the two cases. This difference appears in the lowest pulse 2 velocities (Fig. 11), but not in the pulse 1 . This is consistent with Eqs. (4) and (5) if we identify the pulses with the Lamb modes as above.

\section{$\underline{\text { Lamb Wave Dispersion Plots }}$}

Figure 12 is a Lamb wave dispersion plot calculated from the phase velocity data on a [0] unidirectional $\mathrm{SiC} / \mathrm{RBSN}$ composite tensile specimen. In Fig. 13 this same data is scaled to graphite/polymer values by Eq. (6) and plotted on the dispersion diagram from Fig. 1. To compare Fig. 12 with Fig. 13 assume that: (1) the horizontal axis kh is independent of whether the composite is graphite/polymer or CMC, and that: (2) the vertical axis fh will differ, as discussed earlier, as the ratio of through thickness velocity in the two materials. With these assumptions it appears that both pulse 1 and pulse 2 data fall below their graphite/polymer counterparts. The pulse 1 and pulse 2 data both lie near the lowest antisymmetric mode curve.

Although the Eq. (6) rescaling of the CMC fh data is useful to indicate that pulse 1 and pulse 2 data lie in the lowest regime of the dispersion diagram, their final identification depends upon their dispersion properties. In particular, the pulse 1 data exhibit no dispersion, which is the same as the lowest symmetric mode. The pulse 2 data exhibit negative intercept dispersion, which is the same as the lowest antisymmetric mode. 


\section{$\underline{\text { Lamb Waves and Mechanical Properties }}$}

Thermal degradation in SiC/RBSN causes decrease in both axial modulus and fiber/matrix interfacial shear strength. It was shown in Ref. [2] that these mechanical degradations are observable as decreases in the pulse 1 and pulse 2 group velocities. An example of the effect of this on the dispersion curves is shown in Fig. 14. Here, the pulse 2 (lowest antisymmetric mode), dispersion curve from Fig. 12 is plotted along with the curve for the same specimen after degradation from $1 \mathrm{hr}$ at $600 \mathrm{C}$ in oxygen.

Figure 15 shows pulse 1 dispersion curves for three unidirectional $\mathrm{SiC} / \mathrm{Ti}$ 15-3 panels. As with the CMC data in Fig. 13, we expect the pulse 1 data to correspond to the lowest symmetric Lamb mode at low $\mathrm{kh}$ values. The data were taken for wave propagation along the fiber direction. The three panels each had different thicknesses, ranging from $\mathrm{h}=0.15$ to $\mathrm{h}=0.29 \mathrm{~cm}$. They also had different $\mathrm{SiC}$ fiber fractions ranging from 15 to 45 percent. The three panels were measured with the same pair of $1 \mathrm{MHz}$ broadband transducers and dispersion curves were calculated for the same frequency range. The difference in the slopes, and hence the group velocities, can be taken as evidence that the axial modulus increases with fiber fraction. It becomes apparent from Fig. 15 that, with dispersion calibration curves, one could compare mechanical stiffness parameters of specimens of different thicknesses.

\section{CONCLUSIONS}

Lamb waves can be produced and detected in ceramic matrix composites (CMC) and metal matrix composite (MMC) plates using the acousto-ultrasonic configuration employing broadband transducers.

Based on analysis of dispersion curves the lowest antisymmetric and nondispersive segments of symmetric Lamb wave modes can then be used to reveal variations of longitudinal stiffness and also shear strength in CMC's and MMC's. 
The use of group velocities is more straightforward in application than the use of phase velocities to construct dispersion curves. Dispersion curves reveal fundamental relationships between mechanical properties and the ultrasonic parameters. They allow comparison of specimens of different geometry.

Although a basis has been established for analyzing Lamb wave velocities for characterizing composite plates, further work is needed to establish theoretical geometrical dispersion curves for various $\mathrm{CMC}$ and $\mathrm{MMC}$ systems. Comparison of the AU data for high temperature composites with theoretical dispersion curves for graphite/polymers has some limited value for demonstration purposes. It establishes the dispersion regime of the CMC and MMC data. CMC and MMC theoretical curves are still needed for final verification of individual modes. 


\section{REFERENCES}

1. H.E. Kautz, Mater. Eval., 45:1404 (1987).

2. H.E. Kautz and R.T. Bhatt, NASA TM-103806 (1991).

3. H.E. Kautz and B.A. Lerch, Mater. Eval., 49:607 (1991). Also NASA TM-104339 (1991).

4. B. Tang and E.G. Henneke II, Res. Nondestr. Eval., 1:51 (1989).

5. H. Lamb, Proc. R. Soc. London, A 93:114 (1917).

6. B. Tang and E.G. Henneke II, Mater. Eval., 47:928 (1989).

7. J.H. Hemann and G.Y. Baaklini, NASA CR-3724 (1983).

8. W.R. Rose, S.I. Rokhlin, and L. Adler, Review of Progress in Quantitative Nondestructive Evaluation, Vol. 6B, D.O. Thompson and D.E. Chimenti, eds., p. 1111. Plenum Press, New York (1987).

9. D.E. Chimenti and A.H. Nayfeh, J. Appl. Phys., 58:4531 (1985).

10. W.T. Yost and J.H. Cantrell, Review of Progress in Quantitative Nondestructive Evaluation, Vol. 5B, D.O. Thompson and D.E. Chimenti, eds., p. 1077. Plenum Press, New York (1986).

11. A.K. Mal and Y. Bar-Cohen, Wave Propagation in Structural Composites, Proceedings of the Joint ASME/SES Applied Mechanics and Engineering Conference, AMD-VOL. 90, A.K. Mal and T.C.T. Ting, p. 1. ASME, New York (1988).

12. M.T. Kiernan and J.C. Duke Jr., J. Acoust. Emiss., 8:S179 (1989).

13. B. Tang, E.G. Henneke II, and R.C. Stiffler, Proceedings of Acousto-Ultrasonics: Theory and Application, J.C. Duke Jr., ed., p. 45. Plenum Press, New York (1988).

14. M.T. Kiernan and J.C. Duke Jr., p. 40. NASA CR-185294 (1990).

15. W. Sachse and Y. Pao, J. Appl. Phys., 49:4320 (1978).

16. Roth, D.J., Stang, D.B., Swickard, S.M., and DeGuire, M.R., NASA TM-102501-REV (1990). 
TABLE I.-ESTIMATES OF fh FOR SCALING CERAMIC MATRIX

COMPOSITE DATA WITH THE THREE RANGES OF

TRANSDUCER FREQUENCY EMPLOYED TO

GRAPHITE/POLYMER DISPERSION

CURVES OF FIGURE 1

\begin{tabular}{|c|c|c|c|c|}
\hline $\begin{array}{c}\text { Broadband } \\
\text { transducer } \\
\text { center } \\
\text { frequency, }\end{array}$ & $\begin{array}{c}\text { Specimen } \\
\text { thickness, } \\
\mathrm{h},\end{array}$ & $\begin{array}{c}(\mathrm{fh})_{\mathrm{CMC}}, \\
\mathrm{m} / \mathrm{sec}\end{array}$ & $\begin{array}{c}(\mathrm{fh})_{\mathrm{GP}}= \\
(\mathrm{fh})_{\mathrm{CMC}}\left(\mathrm{V}_{\mathrm{GP}} / \mathrm{V}_{\mathrm{CMC}}\right), \\
\mathrm{m} / \mathrm{sec}\end{array}$ & $\begin{array}{c}\text { Regime of } \\
\text { intercept }\end{array}$ \\
\hline 2.25 & 0.22 & 5000 & 1688 & Dispersive \\
.5 & .22 & 1100 & 372 & Nondispersive \\
1.0 & .22 & 2200 & 473 & Nondispersive \\
\hline
\end{tabular}

$\mathrm{V}_{\mathrm{GP}}$, through thickness velocity in the graphite $/$ polymer $=0.27 \mathrm{~cm} / \mu \mathrm{sec}[3]$.

$\mathrm{V}_{\mathrm{CMC}}$, through thickness velocity in the 30 percent porous $\mathrm{CMC}=0.8 \mathrm{~cm} / \mu \mathrm{sec}$ $[16]$.

TABLE II.--SUMMARY OF MATERIALS USED IN THIS STUDY

\begin{tabular}{|c|c|c|c|c|}
\hline Material $^{\mathrm{a}}$ & Geometry $^{b}$ & Orientation & $\begin{array}{c}\text { Thickness, } \\
\text { h, } \\
\text { cm }\end{array}$ & $\begin{array}{l}\text { Fiber, } \\
\text { vol. \% }\end{array}$ \\
\hline $\begin{array}{l}\text { As-fabricated } \\
\text { SCS-6/RBSN }\end{array}$ & Tensile & {$[0]$} & 0.216 & 30 \\
\hline $\begin{array}{l}\text { As-fabricated } \\
\text { SCS-0/RBSN }\end{array}$ & Tensile & {$[0]$} & .216 & 30 \\
\hline $\begin{array}{l}\text { SCS- } 6 / \mathrm{RBSN} \\
\text { heat treated } \mathrm{O}_{2} \text {, } \\
600 \mathrm{C}, 1 \mathrm{hr}\end{array}$ & Tensile & {$[0]$} & .216 & 30 \\
\hline $\mathrm{SiC} / \mathrm{Ti} 15-3$ & Unipanel & {$[0]$} & .15 & 45 \\
\hline $\mathrm{SiC} / \mathrm{Ti} \mathbf{1 5 - 3}$ & Unipanel & $\begin{array}{c}{[0]} \\
\text { (varied in } \\
\text { Fig. 9) }\end{array}$ & .17 & 34 \\
\hline $\mathrm{SiC} / \mathrm{Ti} 15-3$ & Unipanel & {$[0]$} & .29 & 15 \\
\hline
\end{tabular}

${ }^{\mathrm{a}}$ Information on materials can be found in Refs. [3] and [2].

${ }^{b}$ Tensile specimens were approximately 11.6 by $1.3 \mathrm{~cm}$ by thickness.

There were no grips attached. Panels were at least 5 by $15 \mathrm{~cm}$ by thickness. 


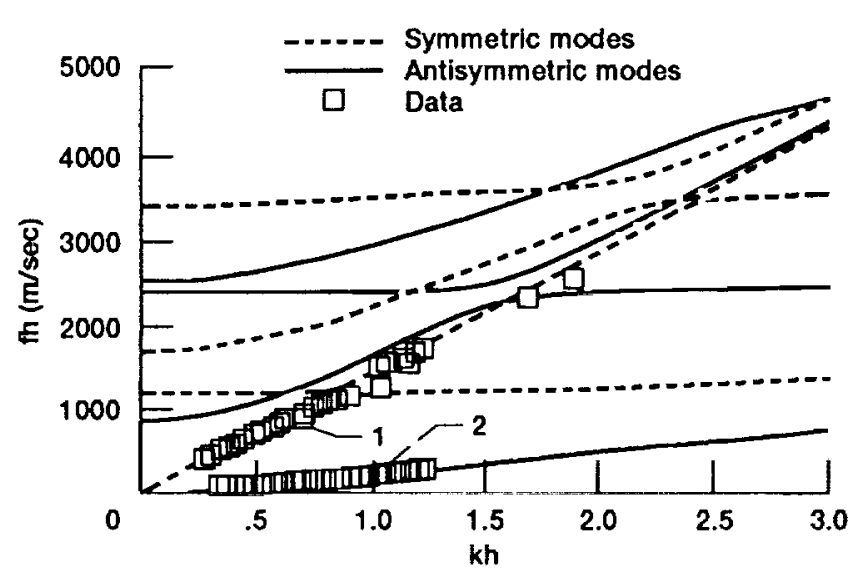

Figure 1.-Theoretical Lamb wave geometrical dispersion curves for propagation parallel to fiber direction of a unidirectional graphite/polymer laminate. The curves are constructed using the approximate theory $\ln$ ref. 4 . $f=$ frequency, $k=$ wave number $(=2 \pi / \lambda)$, and $h=$ plate thickness. Arrows 1 and 2 point to nondispersive Lamb curves.

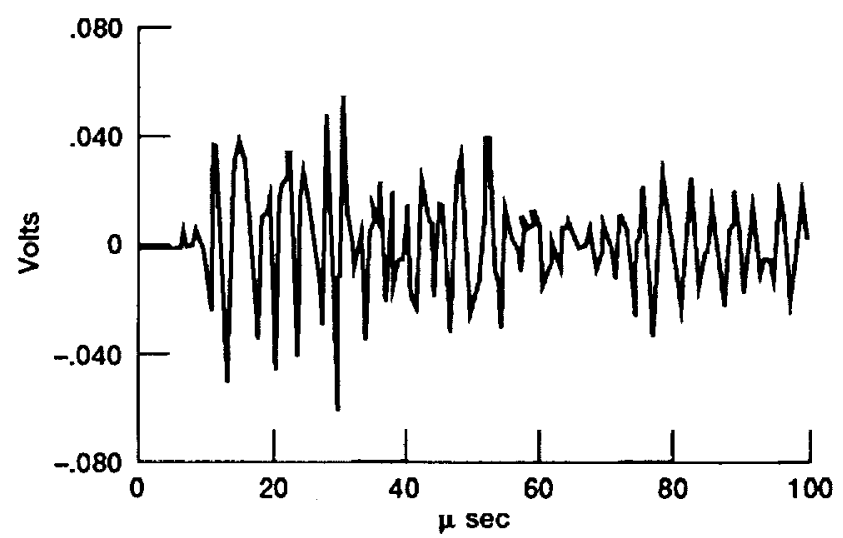

Figure 3.-Waveform collected in acousto-ultrasonic configuration from a [0] unidirectional SiC/RBSN tensile specimen. Transducers: $2.25 \mathrm{MHz}$ broadband sender and recelver. Coupling pressure: $15 \mathrm{~N} / \mathrm{cm}^{2}$.

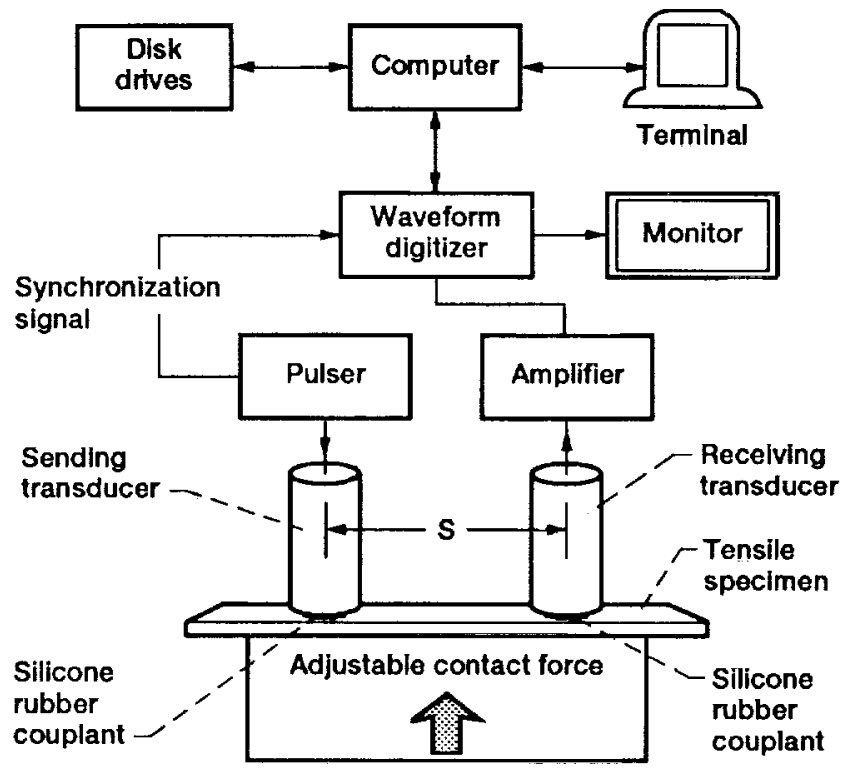

Figure 2.-Acousto-ultrasonic configuration employed for collecting data. $s$ is the centerline spacing between the transducers. $s$ is varied in these experiments.

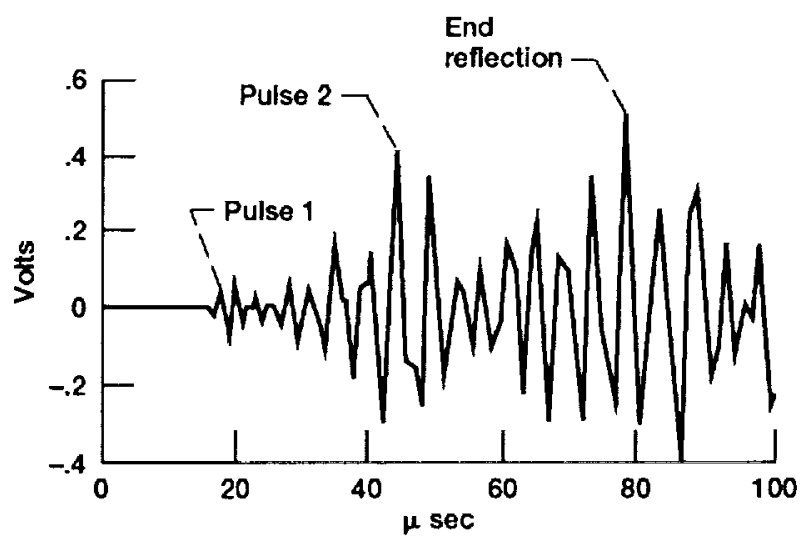

Figure 4--Same specimen as in Figure 3. Transducers: $1.0 \mathrm{MHz}$ broadband sender and receiver. Coupling pressure: $3.5 \mathrm{~N} / \mathrm{cm}^{2}$ 


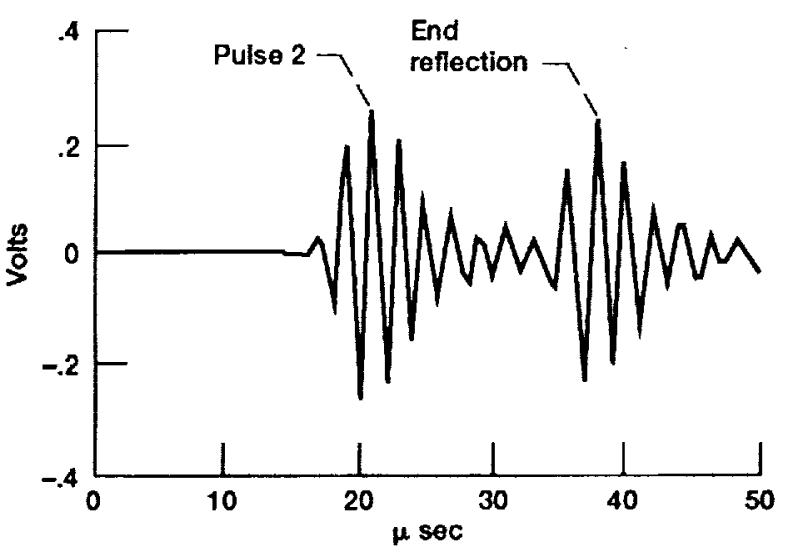

Flgure 5.-Same specimen as in Figure 3. Transducers: $0.5 \mathrm{MHz}$ broadband sender and receiver. Coupling pressure: $3.5 \mathrm{~N} / \mathrm{cm}^{2}$.

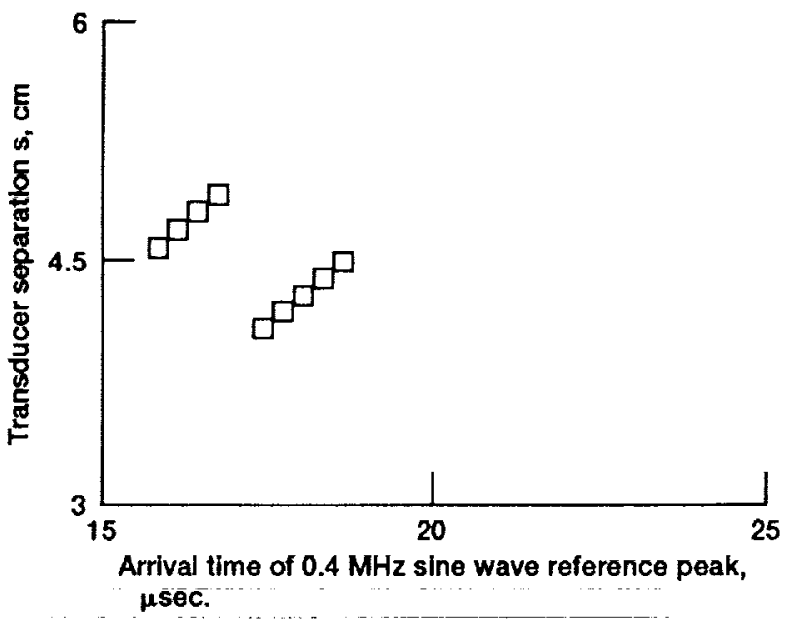

Flgure 7.-Plot of transducer separation, 5 , versus $0.4 \mathrm{MHz}$ frequency component sine wave reference peak arrival. All points shown are assoclated with the same pulse 2 on the same specimen. The plot illustrates the case where, as separation s was increased, to $0.4 \mathrm{MHz}$ sine wave reference peak passed out of the calculation window and was replaced by the next sine wave peak.

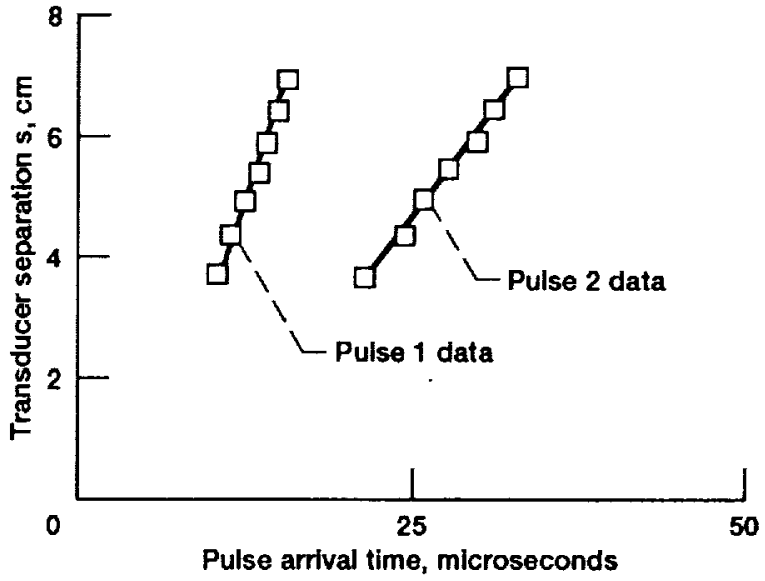

Figure 6.-Typical plots for determining pulse 1 and pulse 2 group velocity, $v_{g}$ from regression slope.

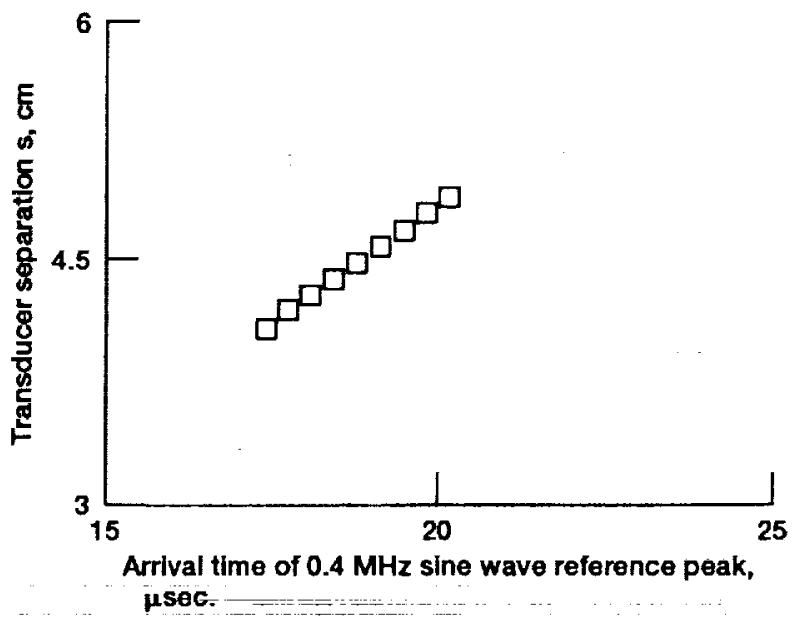

Figure 8.-Plot of the same data as Figure 7. This time when the $0.4 \mathrm{MHz}$ sine wave reference peak arrival has moved out of the window, the calculate arrive, $t_{2}$, has been increased by one cycle, le: $t_{2} \rightarrow t_{2}+1 /(0.4 \mathrm{MHz}$ ). 


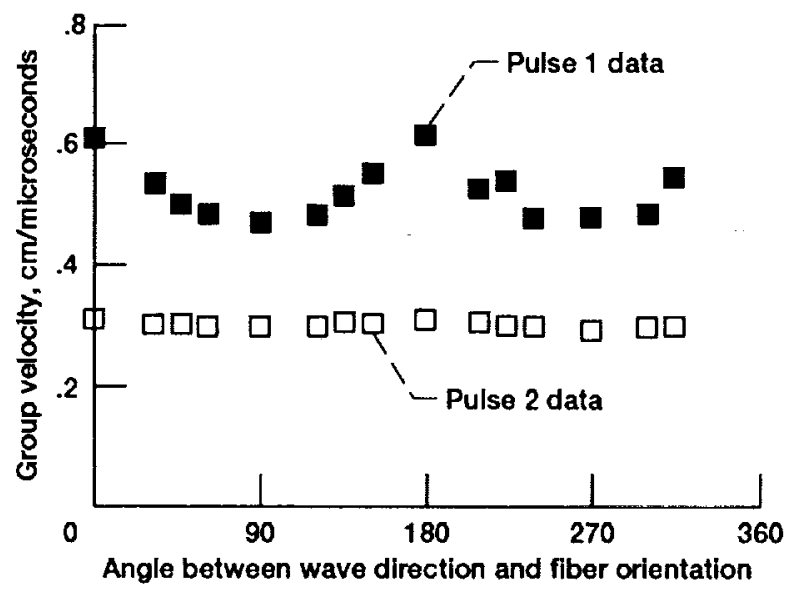

Figure 9.-Pulse 1 and pulse 2 group velocity, $V_{g}$, as a function of the angle, $\Theta$, between wave propagation direction and fiber lay-up direction in a unldirectlonal SiC/TI 15-3 MMC panel. For this panel: Thickness $h=0.17 \mathrm{~cm}$, fiber volume per cent 34 .
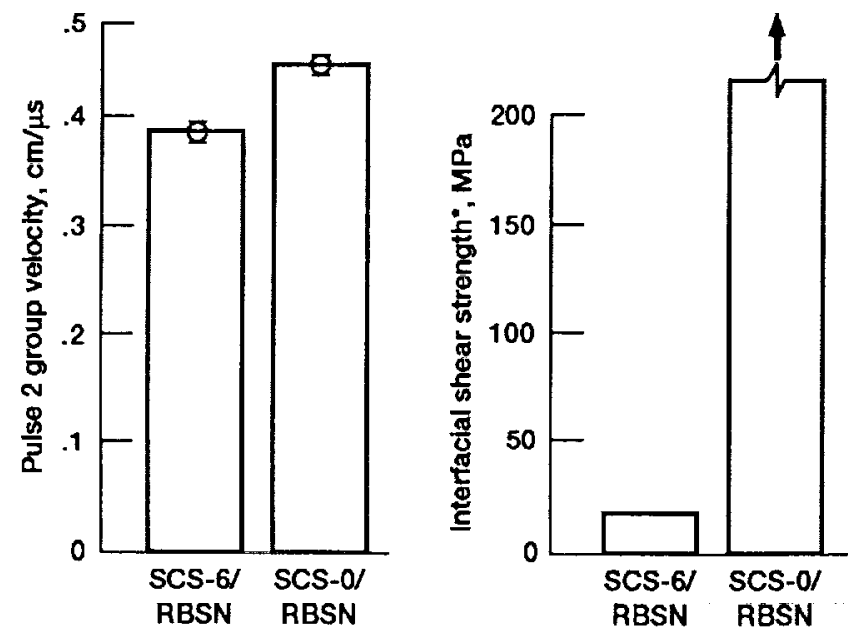

* Measured by fiber push-out method

Figure 11.-Comparison of the response of pulse 2 group velocity, $\mathrm{V}_{\mathrm{g}}$, and of fiber/matrix interfaclal shear strength to type of SiC fibers in SiC/RBSN CMC. Data from ref. 2.

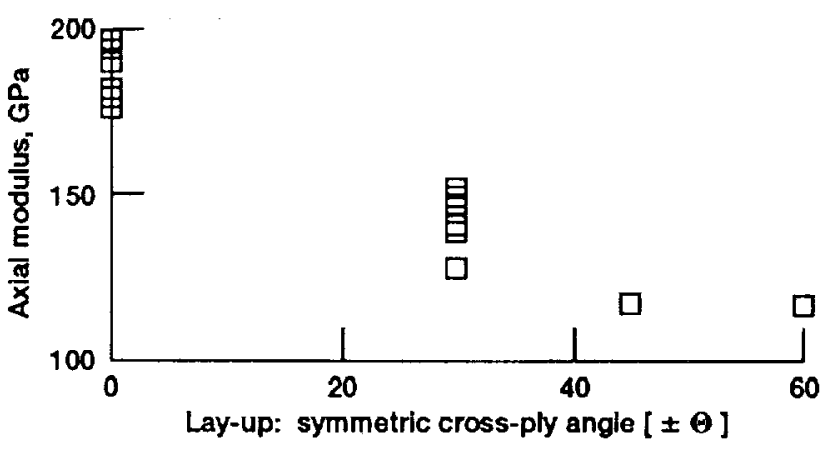

Figure 10.-Axial modulus of $\mathrm{SIC} / \mathrm{T}$ 15-3 MMC as a function of $\Theta$ for flber lay-ups $[ \pm \theta$ ]. Axial modulus data is from destructive tensile tests in ref. 3.

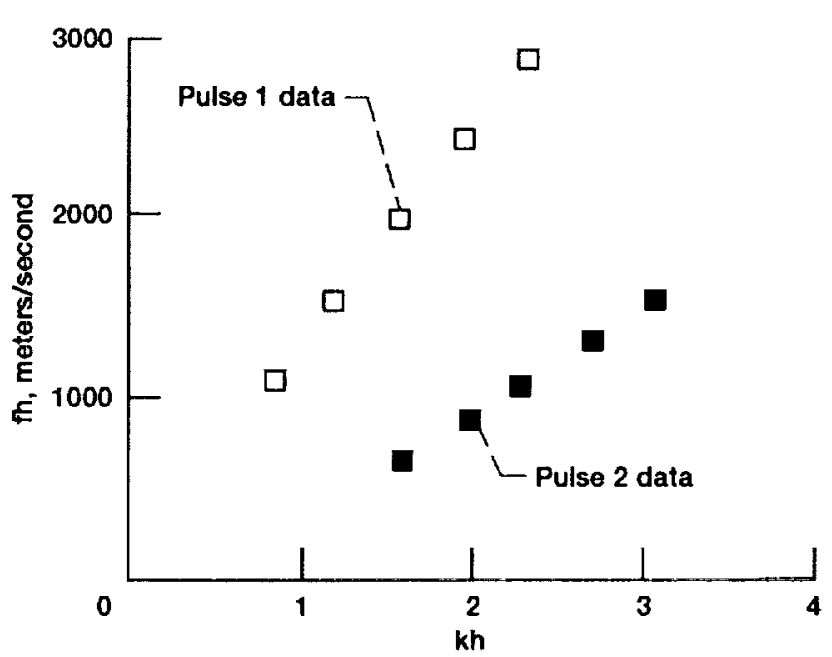

Figure 12.-Experimental Lamb wave dispersion curves calculated for a [0] SiC/RBSN CMC tensile specimen. Calculations were made from broadband transducer accusto-ultrasonic data. 


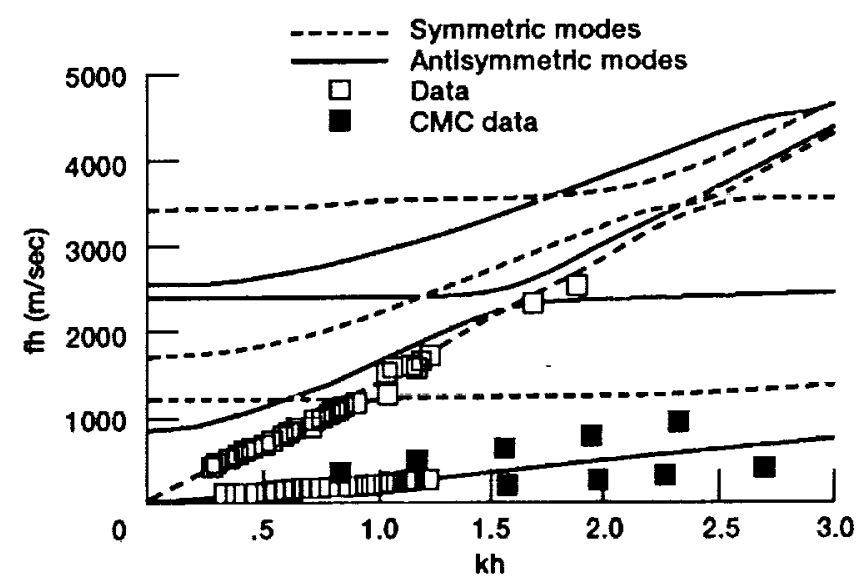

Flgure 13.-Experimental Lamb wave dispersion data from Figure 12. The th values are scaled from SiC/RBSN through thickness velocity to graphite/polymer through thickness velocity by equation 6 . The data are then plotted with theoretical geometrical dispersion curves for graphite/polymer from Figure 1.

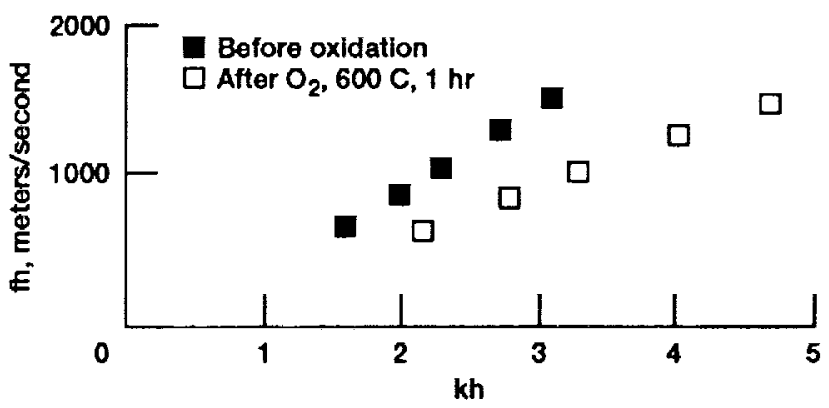

Figure 14.-Plot of the pulse 2 dispersion curve of SIC/RBSN CMC In Figure 12 (before oxidation) and pulse 2 dispersion curve of the same specimen after $600 \mathrm{C}, 1 \mathrm{hr}$, in $\mathrm{O}_{2}$ heat treatment.

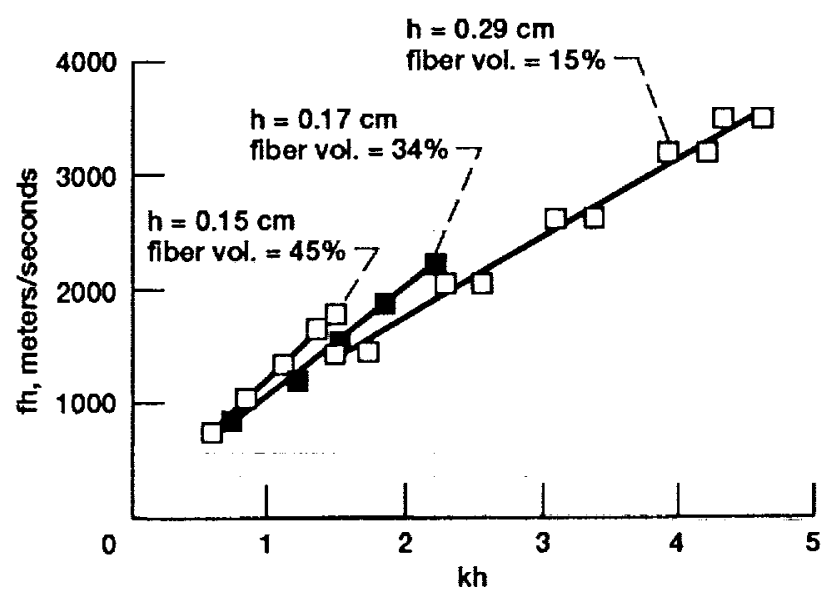

Figure 15.-Experimental pulse 1 dispersion curves constructed from acousto-ultrasonic data on three $\mathrm{SiC} / \mathrm{T}$ 15-3 MMC panels with various thicknesses, $h$, and SiC fiber volume per cent. All data were taken with the same pair of 1.0 $\mathrm{MHz}$ broadband transducers and all three dispersion curves were constructed over the same frequency range: 0.5 to $1.2 \mathrm{MHz}$. 


\section{APPENDIX I.-DETERMINATION OF PULSE ARRIVAL TIMES, $t_{1}$, AND PHASE REFERENCE TIMES, $t_{2}$, FOR CALCULATION OF THE GROUP AND PHASE VELOCITIES}

Figure A1 shows a typical waveform, wf(t), collected on a SiC/RBSN tensile specimen employing two $0.5 \mathrm{MHz}$ transducers. There are two pulses in $w \mathrm{f}(\mathrm{t})$. The earlier is the pulse 2 of Figs. 4 and 5. It is associated with the first antisymmetric Lamb mode and its arrival time is of interest. The later is the echo of pulse 2 after an end reflection. (In many cases the echo is larger than the original pulse 2 because it is the superposition of echoes off the opposite ends when they meet at the receiving transducer.)

Next wf(t) undergoes two processing steps:

(1) Set $w f(t)=$ absolute value $(w f(t))=|w f(t)|$

(2) Average $h_{w} f(t) \mid$ over one cycle of the center frequency of the pulse 2, (in this case average over $1 / 0.48 \mathrm{MHz})$, which gives $\langle(w f(t)\rangle$ plotted it Fig. A2.

With the echoes windowed out, the maximum of $\mathrm{wf}(\mathrm{t})$ is taken as the pulse arrival time, $\mathrm{t}_{1}$. In this example, $t_{1}=13.1836 \mu$ sec. Comparing Figs. A1 and A2 one can see that $t_{1}$ is the maximum of the pulse 2 amplitude but not necessarily a peak in the original pulse 2 of Fig. A1.

Now that $t_{1}$ is determined, it will be the center for two windows used in determining the phase reference time $t_{2}$. Figure A3 is the first step to determining $t_{2}$. We choose in this example to determine a reference time for the frequency $\mathrm{f}=0.4 \mathrm{MHz}$. To this end, a window of the Fig. A1 waveform is constructed for the time interval $t_{1} \pm 1 /(0.4 \mathrm{MHz})$. (As discussed in the text, the square window is thought to less alter phases in the region of $0.4 \mathrm{MHz}$ than would other kinds of windows.)

Figure A4 shows the phase spectrum, $\Phi(\mathrm{f})$, part of the Fourier transform of the waveform in Fig. A3. The phase, $\Phi(0.4 \mathrm{MHz})$, is read off of this phase spectrum. 
Figure A5 shows a constructed sine wave:

$$
\operatorname{sine}[2 \pi(0.4 \mathrm{MHz}) \mathrm{t}+\Phi(0.4 \mathrm{MHz})]
$$

in the windowed interval $t_{1} \pm 0.5 /(0.4 \mathrm{MHz})$. This window contains exactly one cycle of the $0.4 \mathrm{MHz}$ sine wave. Its one peak, $\mathrm{t}_{2}$, is taken as the $0.4 \mathrm{MHz}$ reference time. In this case, $\mathrm{t}_{2}=13.5742 \mu \mathrm{sec}$.

Changes of $t_{1}$ as transducer separation, $s$, is varied determine the pulse group velocity. Changes of $t_{2}$ as $s$ changes determine the $0.4 \mathrm{MHz}$ phase velocity. In practice, not one $t_{2}$ but a set of $t_{2}$ 's are calculated. One is calculated for each of a set of frequencies that are important in the pulse spectrum. From this, phase velocity as a function of frequency is available for the construction of an experimental dispersion curve.

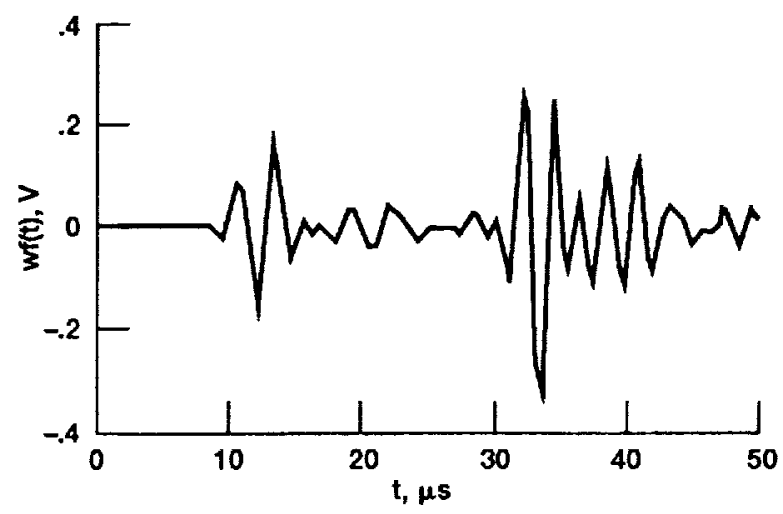

Figure A1.-Typical waveform, wf(t), collected on a SiC/RBSN specimen and employing two $0.5 \mathrm{MHz}$ transducer. It contalns a pulse 2 and a pulse 2 end refiection the same as Flgure 5 .

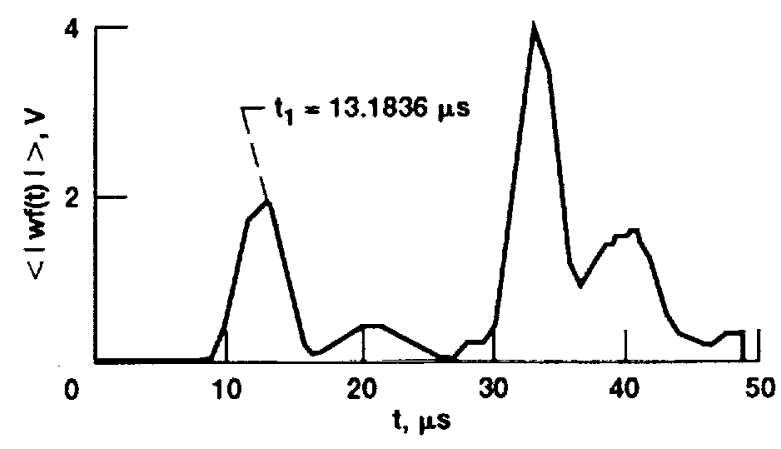

Figure A2.-Function, $\langle|w f(t)|\rangle$, constructed for determining pulse arrival time, $t_{1}$. 


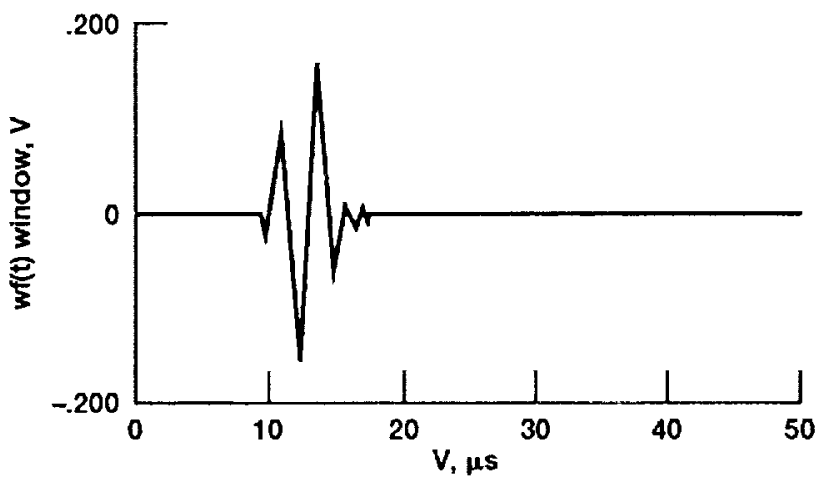

Figure A3.-Square wave windowed wf(t) from A1 .

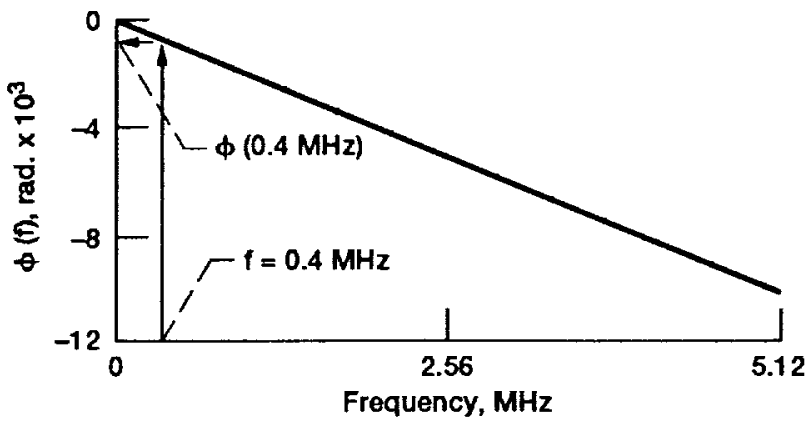

Figure A4.-Phase spectrum of the Fourler transform of the windowed wf(t) in Figure A3.

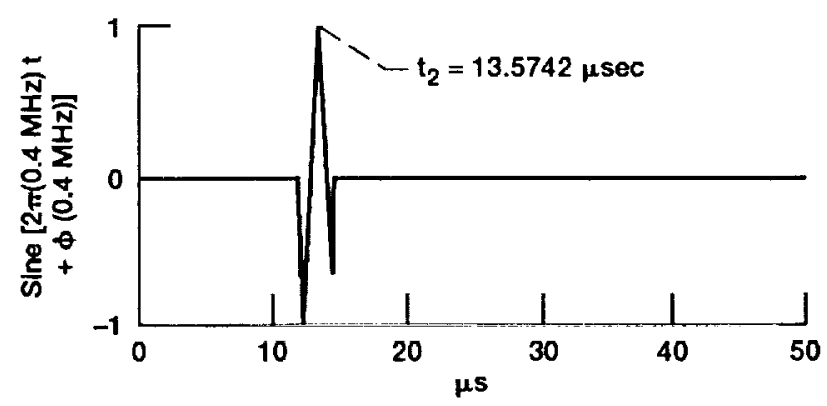

Figure A5.-Constructed sine wave with frequency $0.4 \mathrm{MHz}$ and phase equal to the phase at the $0.4 \mathrm{MHz}$ frequency component of the spectrum of Figure A4. 


\section{REPORT DOCUMENTATION PAGE}

Public reporting burden for this collection of information is estimated to average 1 hour per response, including the time for reviewing instructions, searching existing dala sources, gathering and maintaining the data needed, and completing and reviewing the collection of information. Send comments regarding this burden estimate or any other aspect of this Davis Highway. Suite 1204, Arlington, VA 22202-4302, and to the Office of Management and Budget, Paperwork Reduction Project (0704-018B), Washington, DC 20503.

\begin{tabular}{|c|c|c|}
\hline 1. AGENCY USE ONLY (Leave blank) & $\begin{array}{l}\text { 2. REPOAT DATE } \\
\text { March } 1992\end{array}$ & $\begin{array}{l}\text { 3. REPORT TYPE AND̄ D̄ATES COVEERED } \\
\text { Technical Memorandum }\end{array}$ \\
\hline
\end{tabular}

4. TITLE AND SUBTITLE

Detecting Lamb Waves With Broad-Band Acousto-Ultrasonic Signals in Composite Structures

5. FUNDING NUMBERS

6. AUTHOR(S)

WU $-510-01-50$

Harold E. Kautz

\section{PERFoRMING ORganization NAME(S) AND ADDRESS(ES)}

National Aeronautics and Space Administration

Lewis Research Center

Cleveland, Ohio 44135-3191

9. SPONSORING/MONITORING AGENCY NAMES(S) AND ADDRESS(ES)

National Acronautics and Space Administration

Washington, D.C. 20546-0001

11. SUPPLEMENTARY NOTES

Responsible person, Harold E. Kautz, (216) 433-6015.

12a. DISTRIBUTION/AVAILABILITY STATEMENT

Unclassified - Unlimited

Subject Catcgory 38

\section{ABSTRACT (Maximum 200 words)}

Lamb waves can he produced and detected in CMC and MMC plates using the acousto-ultrasonic configuration cmploying broadband transducers. Experimental dispersion curves of lowest symmetric and lowest antisymmetric modes bchave in a manner analogous to the graphite/polymer theoretical curves. In this study a basis has been established for analyzing Lamb wave velocities for characterizing composite plates. Lamb wave dispersion curves and group velocities were correlated with variations in axial stiffness and shear stiffness in metal matrix composites (MMC) and ceramic matrix composites (CMC). For CMC's, interfacial shear strength was also correlated with the first antisymmetric Lamb mode.
8. PERFoRMING ORGANIZATION REPORT NUMBER

E-6881

10. SPONSORING/MONITORING AGENCY REPORT NUMBER

NASA TM -105557 